\title{
Down-slope cascading modulated by day/night variations of solar heating
}

\author{
Irina P. CHUBARENKO,${ }^{1 *}$ Elena ESIUKOVA, ${ }^{1}$ Natalia STEPANOVA, ${ }^{2}$ Boris CHUBARENKO,${ }^{1}$ Henning BAUDLER ${ }^{3}$
}

${ }^{1}$ Laboratory for Coastal Systems Study, P.P. Shirshov Institute of Oceanology of Russian Academy of Sciences, Atlantic Branch, prospect Mira 1, Kaliningrad, 236022 Russia; ${ }^{2}$ Laboratory of Marine Currents, P.P. Shirshov Institute of Oceanology of Russian Academy of Sciences, Nahimovsky prospect 36, Moscow, 117997 Russia; ${ }^{3}$ Biologishe Station Zingst, Institut für Biowissenschaften, Angewandte Ökologie, Universität Rostock, Mühlenstrasse 27, D-18374 Ostzeebad Zingst, Germany

*Corresponding author: irina_chubarenko@mail.ru

\begin{abstract}
Sloping sides of natural basins favour the formation of cross-shore temperature gradients (differential coastal heating/cooling), which cause significant littoral-pelagial water exchange. Autumnal denser water cascading along a sloping lake boundary, modulated by day/night variations of solar heating is considered numerically, in order to reveal the development of the cascading process in time, spatial structure of the exchange flows, and diurnal variations of volumetric flow-rate of littoral-pelagial exchange flow, as well as to compare its daily maxima at different depths/cross-sections, with known quasi-steady state predictions under constant buoyancy flux. The development of exchange flows progresses through two phases: i) appearance and adjustment to day/night buoyancy flux variations; and ii) quasi-steady exchange, when variations of the flow rate in every next diurnal cycle are more or less the same as the previous day. The duration of the first phase depends on local depth ( 1 day for depths of about $10 \mathrm{~m}, \sim 2$ days for depths 15-25 m, and $\sim 5$ days down to $30 \mathrm{~m}$ for the considered initial linear vertical temperature stratification). Maximum horizontal exchange takes place in the cross-section where the thermocline meets the slope, and the cold down-slope currents detach from the bottom. The location of this cross-section advances off-shore with time, in accordance with the deepening of the upper mixed layer. The existence of a specific coastal circulation cell, with different water dynamics from those above the main part of the slope, is a characteristic feature of horizontal convective exchange. The mean value of the specific volumetric flow rate of the convective exchange, driven by day/night oscillations in its fully developed quasi-steady phase increases almost linearly with local depth, and is about twice as large as the quasi-steady exchange values, predicted by formula $\mathrm{Q}=0.0013 \cdot \mathrm{d}^{1.37}$ ( $\mathrm{Q}$ is measured in $\mathrm{m}^{2} \mathrm{~s}^{-1}$, and local depth above the slope $\mathrm{d}$ in $\mathrm{m}$ ), suggesting that the thermal siphon, energized by oscillating day/night buoyancy fluxes, flushes coastal regions twice as efficiently as the cascading, developing under (more or less) uniform external conditions in field observations and laboratory experiments, which lie behind the given formula. Flushing time in the considered case has an order of 10-60 hours for a littoral zone of 6-30 m depth. Application of convective phase diagrams (e.g., $Q$ vs $\Delta T$ ) is suggested as a convenient way to describe the day/night convective exchange, allowing for visualization of the flow development process, its coherency and the time lag of the development at different depths.
\end{abstract}

Key words: day/night circulation, cascading, littoral-pelagial water exchange.

Received: September 2012. Accepted: January 2013.

\section{INTRODUCTION}

Hydro-physical conditions in the littoral zone of lakes and seas are influenced by various external factors, and are thus very complicated. Competitive differential heating and cooling, wind surges, surface and internal wave forcing, and near-slope processes interfere with one another. In this paper, we discuss some features of horizontal water exchange between shallow and deeper areas, arising in a day/night circle, owing to an alternative formation of differential coastal cooling and heating. Such horizontal temperature differences and the associated water exchange arise regularly in the day/night, synoptic and seasonal rhythms along all the coastal slopes of natural basins (Horsch and Stefan, 1988; Farrow and Patterson, 1993; Sturman et al., 1999; Fer et al., 2002; Farrow, 2004; Lei and Patterson, 2006) and, in fact, form natural background for all other processes. This kind of water exchange can be considered and described principally as a sort of horizontal convection, since it is driven by the difference in temperature (or heat flux) at a horizontal boundary (e.g., Farrow, 2004; Mullarney et al., 2004; Hughes and Griffith, 2008). Generally, it works in the following way: when, as a result of solar heating and/or heat-exchange with the atmosphere, water in the littoral region becomes denser than the open lake water - it cascades down-slope in lake pelagial, when it becomes less dense - it flows off-shore in the upper layers, replaced by an on-shore flow beneath. This thermal siphon is shown to be a very effective mechanism of flushing a lake's littoral zone (Monismith et al., 1990). As a field example of the typical structure of the water temperature field, Fig. 1 displays a cross-section obtained on 2 November 2001, in the littoral zone of Mainau Island, and the adjacent area of lake Constance (see Chubarenko et al., 2003, for details of the field campaign). 
Physically, the cooling from the surface of the basin with a sloping bottom (when water temperature, $\mathrm{T}$, is above that of maximum density, Tmd) generates a flow, which is a combination of vertical convective cells (forced by negative buoyancy flux through the surface) and horizontal exchange, consisting of a down-slope density undercurrent and horizontal compensating flow in the upper layers, which are driven by horizontal pressure gradients (Carmack and Farmer, 1982; Farrow and Patterson, 1993; Farrow, 2004; Chubarenko and Demchenko, 2008; Chubarenko, 2010). These two different processes - vertical convection and horizontal exchange - develop with different celerity and are, to a certain extent, independent of one another. Indeed, there could be episodes of strong surface cooling causing fast overturning, while (larger scale) horizontal transport has not yet developed. However, horizontal temperature/pressure gradients and the associated transport could persist long after the convective overturning has ceased. As a result, at the lake scale, the real flow picture develops out of phase with the external forcing, and with variable time lag, depending on downslope distance (Farrow, 2004; Chubarenko, 2010). Under constant external conditions, the steady state can, finally, only be approached in some general/mean sense when horizontal temperature/density gradients and integral flow-rate become more or less constant, implying the bal- ance of lateral heat transport and vertical heat loss owing to surface cooling (Farrow, 2004; Chubarenko, 2010), whilst the very motions (vertical convective exchange and horizontal currents) remain intrinsically unstable, resulting in the formation of cells, eddies, rolls, etc. In addition, in the field where time and space variations of heat-exchange conditions and bathymetry peculiarities are always the case, flow characteristics, such as instantaneous speed, thickness, or particular velocity profiles, are practically unpredictable, and one can only hope to gain an impression on the general structure of the exchange, and register some particular/instant flow patterns. The most extensive field studies of seasonal cascading (Horsch and Stefan, 1988; Farrow and Patterson, 1993; Sturman et al., 1999; Fer et al., 2002; Chubarenko and Demchenko, 2010) point exactly at the intermittent character of the flow, and the truly convective (irregularly changing) behaviour of the water-exchange pattern.

Since Rossby (1965), there have been several attempts to quantify the quasi-steady-state value of the corresponding horizontal exchange. It was shown using scale analysis of the governing equations (Mullarney et al., 2004), that in a basin with horizontal bottom and temperature/ heat flux variation along the horizontal (upper or lower) boundary, the horizontal volume flux Q (per unit width) is proportional to the Rayleigh number:

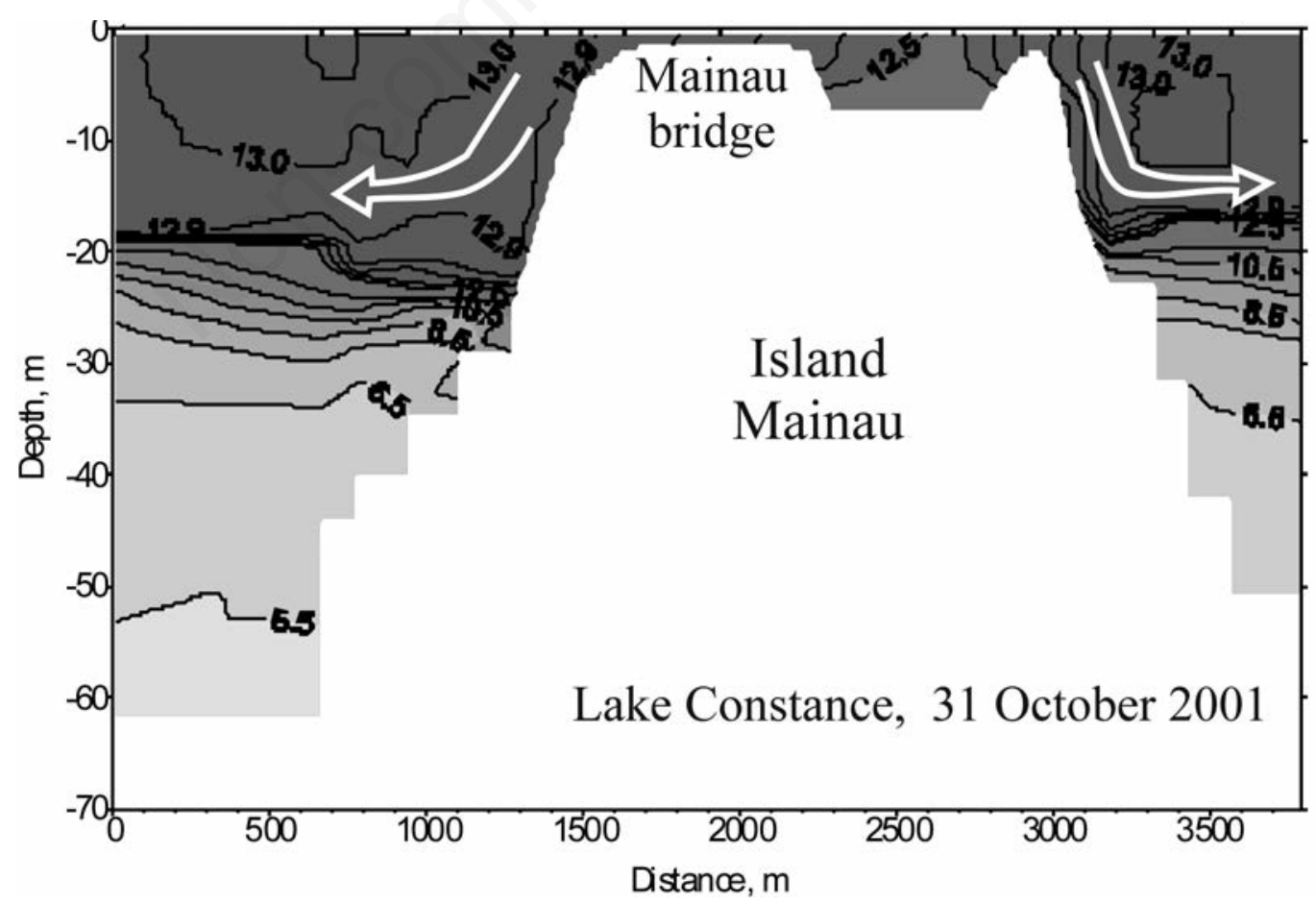

Fig. 1. Vertical transect in the field of water temperature, obtained on 2 November 2001, in littoral zone of island Mainau and adjacent area of lake Constance. The isotherms suggest colder water cascading down-slope on both sides of the island. 


$$
Q \sim R a_{F}^{1 / 6}
$$

where $R a_{F}=\frac{\alpha g F h^{4}}{\rho_{0} c_{p} v k_{T}{ }^{2}}$. Here, $\alpha=-1 / \rho \cdot \partial \rho / \partial T$

is the thermal expansion coefficient of water, $g$ is the acceleration owing to gravity, $F$ is the imposed heat flux, $h$ the length scale, $\rho_{0}$ the reference water density, $10^{3} \mathrm{~kg} \mathrm{~m}^{-3}$, $c_{p}$ the specific heat of water, 4200 Joule $\mathrm{kg}^{-1} \mathrm{C}^{-1}, v$ is the kinematic viscosity, and $k_{T}$ is the thermal diffusivity of water. As for the length scale, a number of spatial dimensions were used in different studies and geometries, including the following: the length of the laboratory tank (e.g., studies in laboratory tanks with horizontal bottom: Rossby, 1965; Mullarney et al., 2004; Hughes and Griffith, 2008); the length of the portion of the bottom that is heated/cooled (forcing plate) or the thickness of the turbulent boundary layer above this forcing plate (Sturman et al., 1999); and the water depth (Horsch et al., 1994; Farrow, 2004; Lei and Patterson, 2006). Studies with sloping bottom (Horsch et al., 1994; Sturman et al., 1999; Farrow, 2004; Chubarenko and Demchenko, 2008; Chubarenko, 2010) have demonstrated the complexity of the arising horizontal convective exchange, which, however, has many common features with Rossby's exchange flows. For example: i) horizontal temperature/density gradient as the driver; ii) characteristic always unsteady behaviour of the quasi-steady exchange; and iii) its 2-layered structure with the maximum speed of currents, observed at intermediate depths rather than at the boundaries (Sturman et al., 1999; Farrow, 2004; Chubarenko, 2010).

Although convective exchange flows in domains with sloping bottom have many common features at different spatial scales, the direct application of formulae such as eq. 1 at the scale of a lake, sea or ocean, is not entirely correct, since spatial scale $h$ enters the $R a$ number in high power, and, formally, any laboratory data (which typically lie behind such dependencies; Rossby, 1965; Mullarney et al., 2004) provide relationships for low $R a$ numbers $\left(10^{3} \div 10^{5}\right)$, whilst for a typical lake/sea scale one has values of the order of at least $R a \sim 10^{12} \div 10^{15}$. In addition, the applicability of water molecular viscosity and diffusivity at such a scale is also questionable. To avoid this difficulty, one may find it profitable in this situation to go back to physical/dimensional expressions of $Q$-dependencies. Using this idea, Sturman et al. (1999) found that the flow is insensitive to variations in the buoyancy flux, and only moderately sensitive to the slope angle. Furthermore, Chubarenko (2010) found that the spatial scale of the problem is the most significant. Taking the best linear fit (with $\mathrm{R}^{2} \sim 0.96$ ) of laboratory, numerical and field measurement data of many authors, she suggested the relationship between the quasisteady flow-rate $Q$ and local water depth $d$

$$
Q=0.0013 \cdot d^{1.37}
$$

which is valid for the typical geophysical values of the buoyancy fluxes in the depth range $10^{-2} \mathrm{~m}<d<3 \cdot 10^{2} \mathrm{~m}$ ( $\mathrm{d} \leq \mathrm{D}$ - local depth above the slope, $\mathrm{D}$ is the full depth of the thermally affected layer). Here, $Q$ is measured in $\mathrm{m}^{2} \mathrm{~s}$ ${ }^{1}$, and $d-$ in $\mathrm{m}$. This relationship is in good agreement with that of Sturman et al. (1999), who predicted the law $Q=B^{1.3} d^{1.33}$ (rewritten here for small-bottom slopes, and in our notation) for slopes between 0.4 to 22 degrees, where $B=g \alpha F / \rho c_{p}$ is the buoyancy flux through the surface, expressed in $\mathrm{m}^{2} \mathrm{~s}^{-3}$.

Such formulae are certain thumb rules, and only give a rough estimate of a convective water-exchange flow rate in its quasi-steady state. In addition, however, they provide important information on general features of the littoralpelagial exchange picture; namely: i) the flow-rate increases with time of cooling, together with the depth of the upper convectively mixed layer $\mathrm{D}(\mathrm{t})$; and ii) spatially, the maximum flow rate is associated with the end of the slope (or, in stratified basin, with the region where the base of the upper mixed layer (UML) meets the sloping bottom).

The main goal of this paper is to consider the temporal and spatial development of the convective exchange flow, not in steady-state but under more common natural conditions of day/night variations of external buoyancy flux, and, particularly, to compare the value of the quasi-steady flow rate, predicted by eq. 2, with instant and mean values obtained in the day/night circle of the cascading process. For simplicity, we consider water at a temperature $\mathrm{T}$ above that of maximum density, so that cooling from the surface produces denser water in the shallows (autumnal situation). The results are also applicable to waters at $\mathrm{T}<\mathrm{Tmd}$, but then the cascades are generated by surface heating (early spring situation) (Chubarenko and Demchenko, 2008; Chubarenko, 2010).

\section{Numerical model}

A three-dimensional, non-hydrostatic (via the artificial compressibility approach; Chorin, 1967), hydrodynamic numerical model MIKE3-FlowModel (DHI Water \& Environment, http://www.dhi.dk) was applied, to simulate the processes in an ideal fresh-water basin, with an initial linear vertical temperature profile. MIKE 3 is a general hydrodynamic numerical modelling system, developed for a wide range of applications in oceans, coastal regions, estuaries and lakes. It simulates unsteady three-dimensional free-surface flows, taking into account density variations, bathymetry and external forcings, which, in our case, are solar radiation, heat exchange with the atmosphere and the Earth's rotation. The hydrodynamic module solves the mass conservation equation, the Reynolds-averaged NavierStokes equation, including the effects of turbulence and 
variable density, and the conservation equations for salinity and temperature in three dimensions, together with the equation of state of sea water, relating the local density to salinity, temperature and pressure.

For the problem under consideration, the heat exchange through the surface was modelled via: i) incoming solar radiation (with day-night variations) corresponding to midlatitudes in September, with $70 \%$ cloudiness; ii) turbulent heat exchange with cooler air (Tair $=7^{\circ} \mathrm{C}$, constant for day and night), calculated for wind speed of $5 \mathrm{~m} \mathrm{~s}^{-1}$; and iii) infrared irradiation. The intensity of the radiation from the sun (short-wave radiation) depends, in the model, on the distance from the sun and day length (i.e., the date), declination angle (time of the day), latitude, extraterrestrial radiation, the cloudiness and amount of water vapour in the atmosphere. Turbulent heat exchange with cooler air (or sensible heat flux, or the heat flux as a result of convection) depends on the type (stability) of the boundary layer between the water surface and the atmosphere, which under the considered conditions was more or less constant; about 150-200 $\mathrm{W} \mathrm{m} \mathrm{m}^{-2}$. Infrared irradiation is calculated as the long-wave emittance from the water surface to the atmosphere, minus the long-wave radiation from the atmosphere to the water, which depends on the cloudiness, air temperature, vapour pressure in the air and relative humidity. Evaporation/precipitation were excluded, as well as wind forcing (wind speed was encountered only in the heat exchange module, but the momentum transfer was excluded). In MIKE3, the heat (light) is allowed to penetrate the water column, which is described through the modified Beer's law, and specified by a light extinction coefficient. If part of solar energy reaches the bottom, it is redistributed uniformly through the entire local water depth, otherwise, sloping, bottom and vertical basin boundaries are insulated.

Overall, the heat exchange conditions in the model are quite complicated, attempting to reproduce natural processes. At the same time, and even though the initial water surface temperature $\left(13^{\circ} \mathrm{C}\right)$ and the value of initial vertical temperature gradient $\left(\mathrm{dT} / \mathrm{dz}=0.15^{\circ} \mathrm{C} \mathrm{m}^{-1}\right.$, Fig. 2$)$ resemble that of lake Überlingen (sidearm of lake Constance), in autumn 2001 (Chubarenko et al., 2003), the idea of this paper is to investigate the process, rather than reproduce the particular case. This is because the convective exchange by itself is quite a complicated phenomenon. The (intrinsically unstable) flows are very inertial and respond to external forcing with a substantial lag, depending on local depth (Sturman et al., 1999; Farrow, 2004; Chubarenko, 2010). As a result, variations of solar radiation alone cause a complicated response, which should first be understood per se.

The choice of the simplified principal wedge-shaped bathymetry of the model basin is pre-conditioned by the same purpose. The basin was taken to be $1 \mathrm{~km}$ wide, $4 \mathrm{~km}$ long, and $50 \mathrm{~m}$ deep, with one $2.5 \mathrm{~km}$-long sloping side (regular bottom slope of about $1^{\circ}$, or $\mathrm{A}=0.02$ ). Another (deeper) side was closed by a vertical insulated impermeable wall (Fig. 3). A rectangular, numerical grid had $80 \times 20$ cells, with grid spacing $50 \mathrm{~m} \times 50 \mathrm{~m}$, and 50 layers in vertical ( $1 \mathrm{~m}$ each); time step of integration was $3 \mathrm{~s}$; simulations started at model noon, 12:00, and lasted for about five weeks. Turbulence was modelled via a Smagorinsky formulation, which links the subgrid scale eddy viscosity to a filter size (grid spacing) and the velocity gradients of the resolved flow field, thus allowing for different mixing coefficients in horizontal and vertical directions. a)

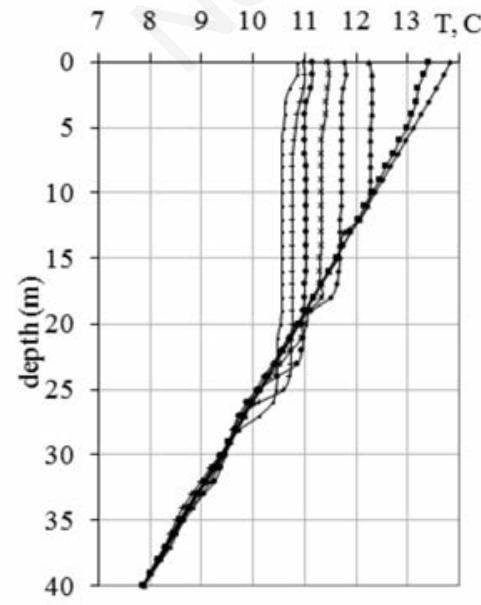

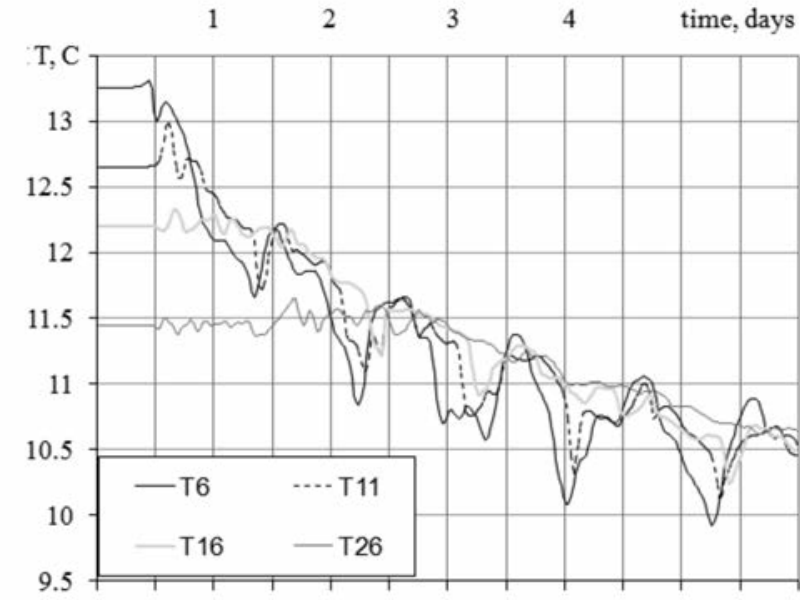

b)

Fig. 2. Progressive cooling in the model basin: (a) modification of vertical temperature profile in deep lake part with time: initial linear profile (straight line) and the development of the upper convectively mixed layer during one week (instant profiles at noon of every day); (b) near-bottom temperature variations with time at depths $6,11,16$ and $26 \mathrm{~m}$. 

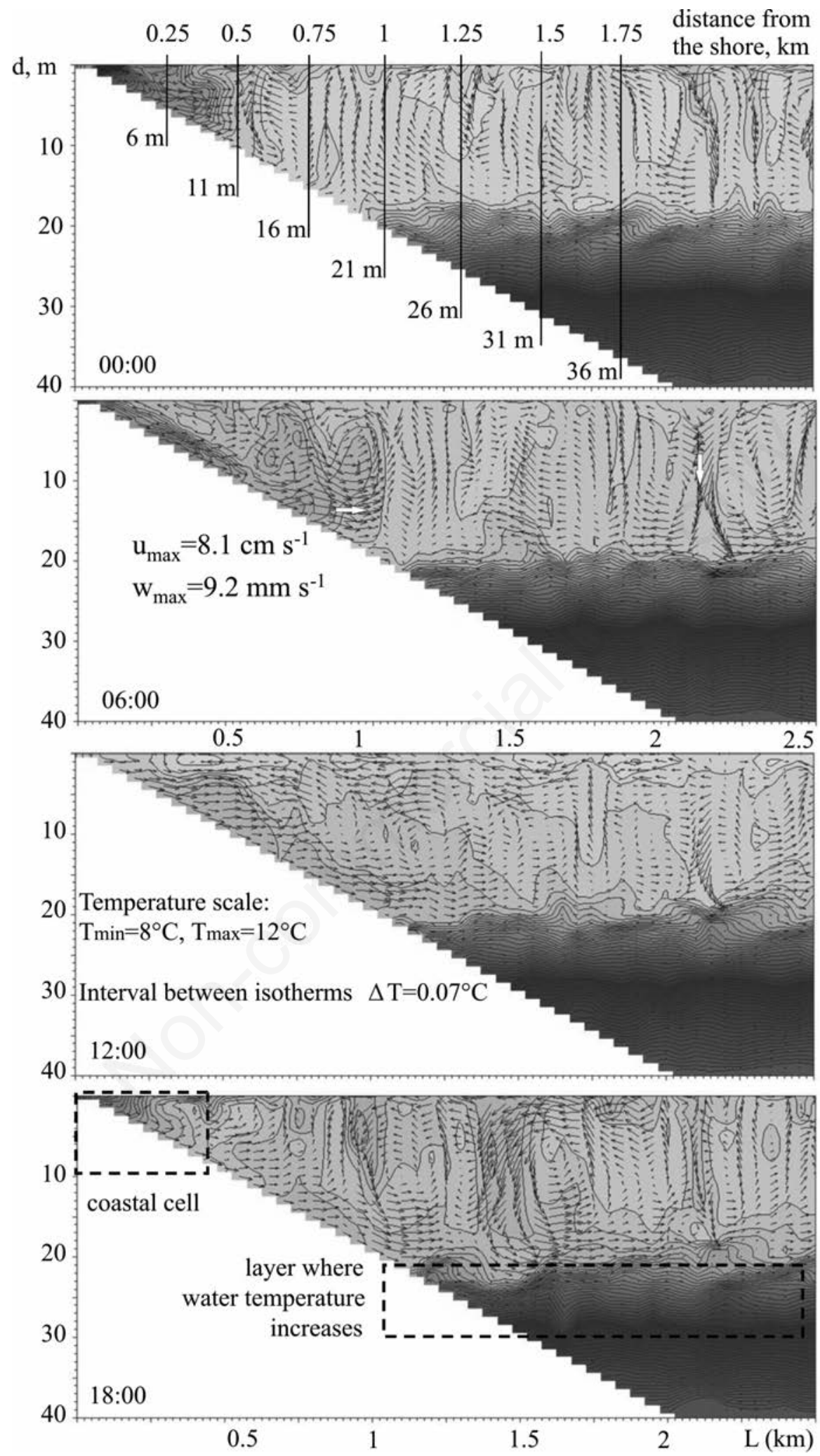

Fig. 3. Instant fields of water temperature and flow velocity at 00, 6, 12 and $18 \mathrm{~h}$ (local time) of the fourth day of the simulation of the cooling process. The cross-sections used in Fig. 2 and that analysed further in the text are shown in the top panel; horizontal $\mathrm{u}_{\max }$ and vertical $\mathrm{w}_{\max }$ maximum velocities (second panel) and specific regions, discussed in the text (bottom), are shown. Note that only the sloping part of the basin is shown; total length of the basin is $4 \mathrm{~km}$, total depth is $50 \mathrm{~m}$, and width is $1 \mathrm{~km}$. 
The modelled heat-exchange conditions caused a quite mild water temperature rise during the daytime, with maximum surface temperatures from 11:30 a.m. to 13:30 p.m. (model noon is at 12:00), and significant temperature decrease during the night, with minimum surface temperatures from 5:30 to 6 a.m. (but sometimes close to midnight, at 1 a.m.). Both differential heating (about $\left.0.03^{\circ} \mathrm{C} \mathrm{km}^{-1}\right)$ and cooling $\left(0.37^{\circ} \mathrm{C} \mathrm{km}^{-1}\right)$ were formed at the water surface above the sloping side (Fig. 3). The latter value is comparable with $0.5^{\circ} \mathrm{C} \mathrm{km}^{-1}$, found by Fer et al. (2002), in measurements from December 1998, in lake Geneva. Overall the decrease of water temperature in the upper layer of the model was about $0.3-0.4^{\circ} \mathrm{C} \mathrm{day}^{-1}$, and deepening of the UML amounted to about 1-2 $\mathrm{m}^{-1 a y^{-1}}$ (Fig. 2), which corresponds to a quite moderate cooling process (for comparison: $0.2-0.4^{\circ} \mathrm{C}$ day $^{-1}$ and $0.4-20 \mathrm{~m}$ day $^{-1}$ in September-October 1972, in lakes in British Columbia (Carmack and Farmer, 1982), or $0.2^{\circ} \mathrm{C} \mathrm{day}^{-1}$ and $3 \mathrm{~m} \mathrm{day}^{-1}$ in October-November 2001, in lake Constance (Chubarenko et al., 2003). Thus, the modelled situation is quite typical for natural autumnal cooling process in lakes at mid-latitudes.

\section{RESULTS AND DISCUSSION}

\section{Structure of the circulation pattern}

The cascading process with a distinct day/night rhythm of (always unsteady) exchange flows (Fig. 3) was analysed over two weeks. Generally, the simulations show intense vertical mixing during night and morning (from 9-11 p.m. to 10 a.m.-12 p.m.), which is replaced by stronger horizontal exchange during daytime. Significant horizontal on- and off-shore flow velocities (about 2-3 $\mathrm{cm} \mathrm{s}^{-1}$, up to $8 \mathrm{~cm} \mathrm{~s}^{-1}$ ) appear in the upper layer, and immediately above the thermocline. To show this more clearly, Fig. 4 presents examples of instant vertical profiles of water temperature, together with the along-slope component of horizontal flow velocity. It is obvious that the subsurface layer and the lower part of the mixed layer, together with the upper thermocline, are regions of maximum horizontal exchange, generated by cooling over a sloping bottom (no wind in simulations). Within two weeks, the initial linear temperature profile (Fig. 2a) was transformed by the cooling process into a more realistic shape: i) upper isothermal layer; ii) sharpened thermocline; and iii) modified remain-
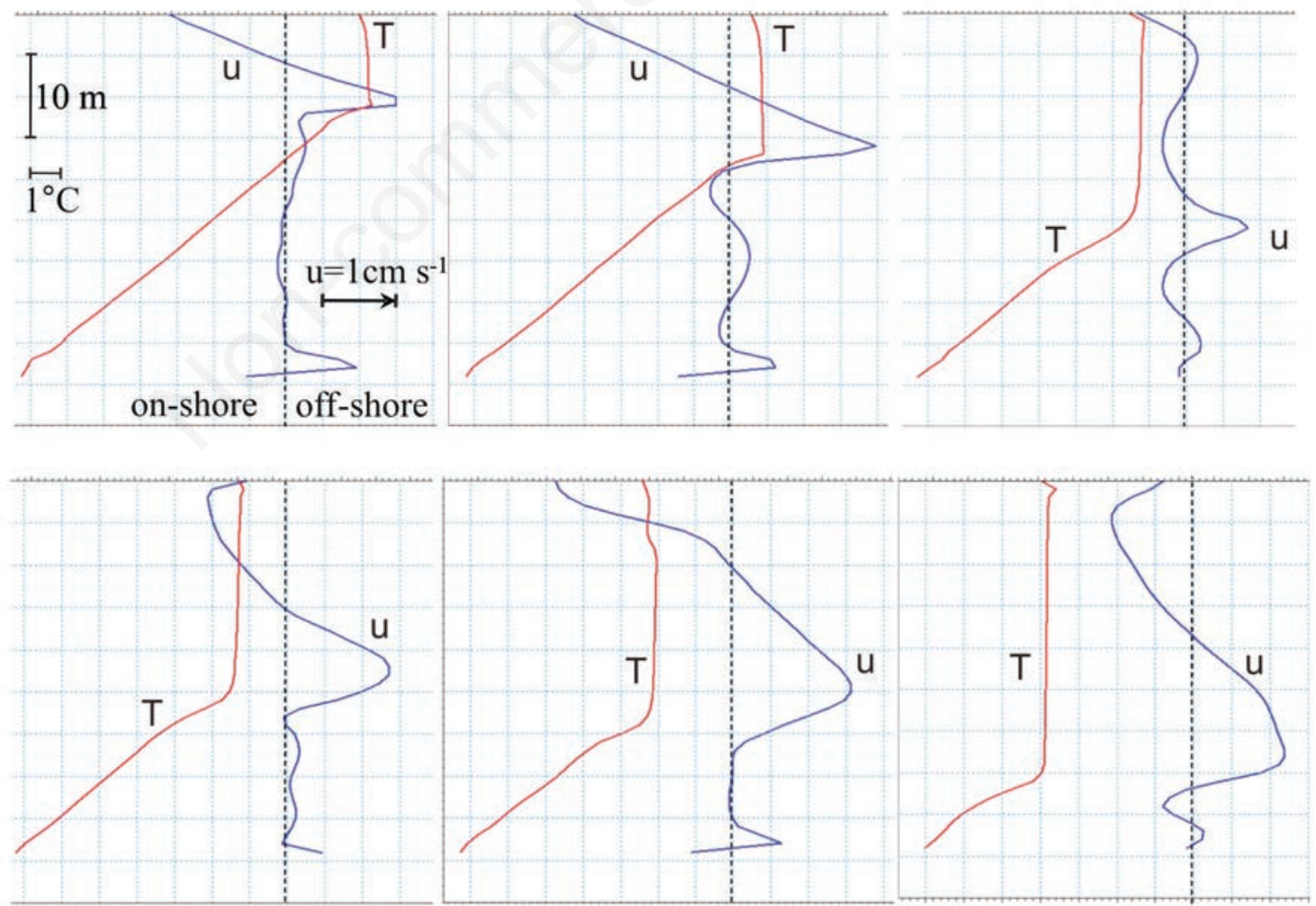

Fig. 4. Examples of instant vertical profiles of water temperature and horizontal (cross-shore) component of water current in deep part of the basin (local depth $46 \mathrm{~m}$ ). The chosen instants are (first line, left to right): 21:30 of the second day of the simulation, 02:30 (fifth day), 02:00 (twelfth day); second line: 20:00 (twelfth day), 21:30 (sixteenth day), 00:30 (thirty-first day). Vertical dashed line marks zero flow velocity. 
der of the initial profile in deeper layers. Interestingly, immediately below the base of the UML (in the upper thermocline) there is a 5-7 m thick layer, where water temperature first increases for some time, and then drops rapidly, when the layer is drawn into vertical mixing from the surface (Figs. 2b and 3). This is exactly the feature pointed out by Carmack and Farmer (1982) in their measurements in lakes in British Columbia.

General flow structure can be described as a combination of large vertical (Bénard-like) convective cells, cold down-slope undercurrent of variable intensity (which can, from time to time, be replaced in some regions by an upslope flow), and a return flow in upper layers. Vertical convective cells (Fig. 3) develop throughout the full thickness of the UML. They are not like steady gyres or rolls, rather they fluctuate around certain positions, the most active being the geometrical end of the basin bottom slope (Fig. 3; the end of the sloping bottom part is at the position $2.5 \mathrm{~km}$ off shore). It is quite surprising: this point is located in deeper layers, well below the thermocline, and is not yet affected directly by vertical mixing or cascading flows. Another, slightly less active, region is that above the point, where the thermocline meets the slope and cold down-slope currents detach from the bottom. Its location advances off-shore with time, in accordance with the deepening of the UML. This point marks the end of the effective slope (Fig. 3), which contributes physically to the formation of colder waters, and whose length/depth is used further in the following Section Flow-rate of horizontal exchange in attempts to quantify the flow rate.

In the basin part, where vertical convection reaches the bottom (i.e. above the effective slope), a spectacular flow separation feature from the bottom boundary (Sturman et al., 1999) appears to be an intrinsic property of the flow: maximum flow velocities are significantly lifted up from the bottom (to $\sim 0.1-0.15$ of the local depth; Chubarenko and Demchenko, 2008; Chubarenko, 2010). This feature provides insight into the physical nature of the flow. Scaling with local depth is characteristic of convective exchange flows, but not of gravity currents, where the thickness of the bottom boundary layer depends on water velocity and bottom-induced turbulence. Indeed, for convective exchange and for gravity currents the physical situation is different. For convection over sloping boundary, there is no one water (gravity current) moving below another water (environment of the current). Here, the entire region over the slope is prone to vertical convection down to (practically) the very bottom, and its horizontal drift in different layers is prescribed by larger-scale horizontal pressure gradients, rather than local density differences. In the coastal triangle above the slope, there is no intrusion of coastal water into the deeper part, but a slow and permanent complete renovation of waters, drifting horizontally with slightly different speeds in different lay- ers. In this way, the convective approach seems to be a more adequate model for general cascading exchange description than the gravity current approach.

Another typical feature of the circulation (emphasized in Fig. 3, bottom), is the presence of a coastal cell in the shallowest part of the slope. While general water circulation in the main part of the region above the sloping bottom is organized as a single whole, and driven by the cooling process, this top-most area has a specific circulation. Farrow (2004) and Monismith et al. (1990) pointed out that, because heating/cooling-induced currents significantly lag after the external forcing, and the day/night rhythm of changes is quite fast for large lakes, the presence of two circulation cells in sloping region is natural and can be explained as follows: in the shallow part, the flow responds quickly to external conditions, and this region is embraced by the coming (e.g., heating-type) circulation, whilst the rest of the sloping region is still experiencing past (cooling-type) circulation. Analysis of the present numerical solutions suggests that the size of this region scales with the mixing depth, so that the horizontal extent of the cell is about $1 / 4-1 / 3$ of the length of the effective slope (e.g., of the (horizontal) distance from the shore to the point at the bottom, where the base of the upper convectively mixing layer meets the slope). Most probably, this is related to the depth of maximum of mean on-shore transport from the deeper lake part, which is formed at the level of approximately $1 / 4-1 / 3$ of the depth of the UML (Chubarenko and Demchenko, 2008; Chubarenko, 2010). In fact, the existence of such a specific circulation cell on the top is a common feature of all convective problems in triangular enclosures, and has been explained in various situations by several different reasons: by mathematical discontinuity in theory (Chubarenko and Hutter, 2005); by the influence of water heat conduction (rather than convection, working in the main sloping region) in laboratory experiments (Farrow, 2004); by shallowness and subsequent plane circulation in 3D numerical modelling (Chubarenko and Demchenko, 2010); and by wave-breaking or river inflow in field data. Whatever reason is valid in a particular case, the following conclusion stands: the existence of a specific coastal circulation cell, with water dynamics different from that above the main part of the slope, is a characteristic feature of horizontal convective exchange flows in coastal regions. We stress here, once again, that global littoral-pelagial (or shelf/sea) water exchange is driven by processes above the main part of the slope, rather than in this most shallow coastal cell.

\section{Instant flow features}

Convective exchange flows in natural basins are known as quite difficult phenomena for quantitative description. This is mainly because the convective currents observed in the field at a limited number of stations are always highly 
variable in time and space, and there is no possibility to monitor the entire region at once, and grasp the whole picture. Fig. 4 illustrates this flow variability, with examples of instant vertical profiles of cross-shore components of the current in the deep part of the basin (local depth $46 \mathrm{~m}$; the thickness of the UML can be inferred from the corresponding instant temperature profiles). General (and already described above) on-shore/off-shore transport in the upper/lower part of the mixed layer is the only (more or less) permanent feature, while the velocity profile, speed of current, and level of the velocity maxima are highly variable.

Temporal variability in the day/night circle of near-bottom current (averaged over $30 \mathrm{~min}$ ) at several locations in $1.5 \mathrm{~m}$ above the sloping bottom, is characterized by curves $u(t)$ in Fig. 5. The presented period covers two days: the third and fourth days of simulations. The depth of the UML during these days has increased from 11 to $16 \mathrm{~m}$ (see Fig. $2 \mathrm{a}$ for vertical temperature profiles). Along with general cooling-driven 24-h oscillation, the flow manifests many other signals. Maximum cooling-induced (down-slope) current velocity is associated with the end of the effective slope, which is at about $11 \mathrm{~m}$ depth during the third day, and about $16 \mathrm{~m}$ during the fourth day (Fig. 5). Both maximum velocities are about $5.5 \mathrm{~cm} \mathrm{~s}^{-1}$ and are observed at about 6 a.m. Both on-shore and off-shore from this point the velocity maxima become smaller and shifted in time (from 6 a.m.), indicating that the time lag is increasing with distance from the shore. Note that the daily maximum velocity at $11 \mathrm{~m}$ depth $\left(u_{11}\right)$ became somewhat smaller the next day, when the depth of the UML increased to $16 \mathrm{~m}$.
This is to emphasize that it is the end of the effective slope where the maximum horizontal exchange takes place.

Of interest for many applications are questions about how far from the shoreline/end of the slope, and how deep below the thermocline level, this exchange is still significant. To this end, one can see in Fig. 5 that maximum exchange velocity at the end of the effective slope $\left(u_{11} \sim 5.5\right.$ $\mathrm{cm} \mathrm{s}^{-1}$ at 6 a.m. of the third day) is only 1.6 times larger than the maximum near-bottom velocity at the depth of $26 \mathrm{~m}\left(\mathrm{u}_{26} \sim 3.5 \mathrm{~cm} \mathrm{~s}^{-1}\right.$ at $6 \mathrm{pm}$ of the third day), which is 2.4 times deeper and $1.4 L$ further off-shore ( $L$ is the length of the effective slope). Both in lakes and the ocean, such horizontal isopycnal exchange is well known as a mechanism which transports littoral waters very far from the coast (Imberger and Hamblin, 1982; Thorpe, 1998).

Since the denser water cascading down-slope interleaves upon their detachment from the slope into the stratified environment as turbulent intrusion, it is separated dynamically from the layers above and below it, so may propagate for a long distance along the isopycnal surface, until its kinetic energy is dissipated through turbulent mixing and entrainment of surrounding water at the boundaries (Baines, 2001, 2005). In a stratified liquid, turbulent mixing between the body of such intrusions and the underlying/overlying layers is suppressed by buoyancy forces. Thus, the more the environment is stratified, the less kinetic energy of the flow is dissipated by generated turbulence. The overall conclusion for the process under consideration is that both the depth and the distance of influence of cooling-induced cascades depend physically

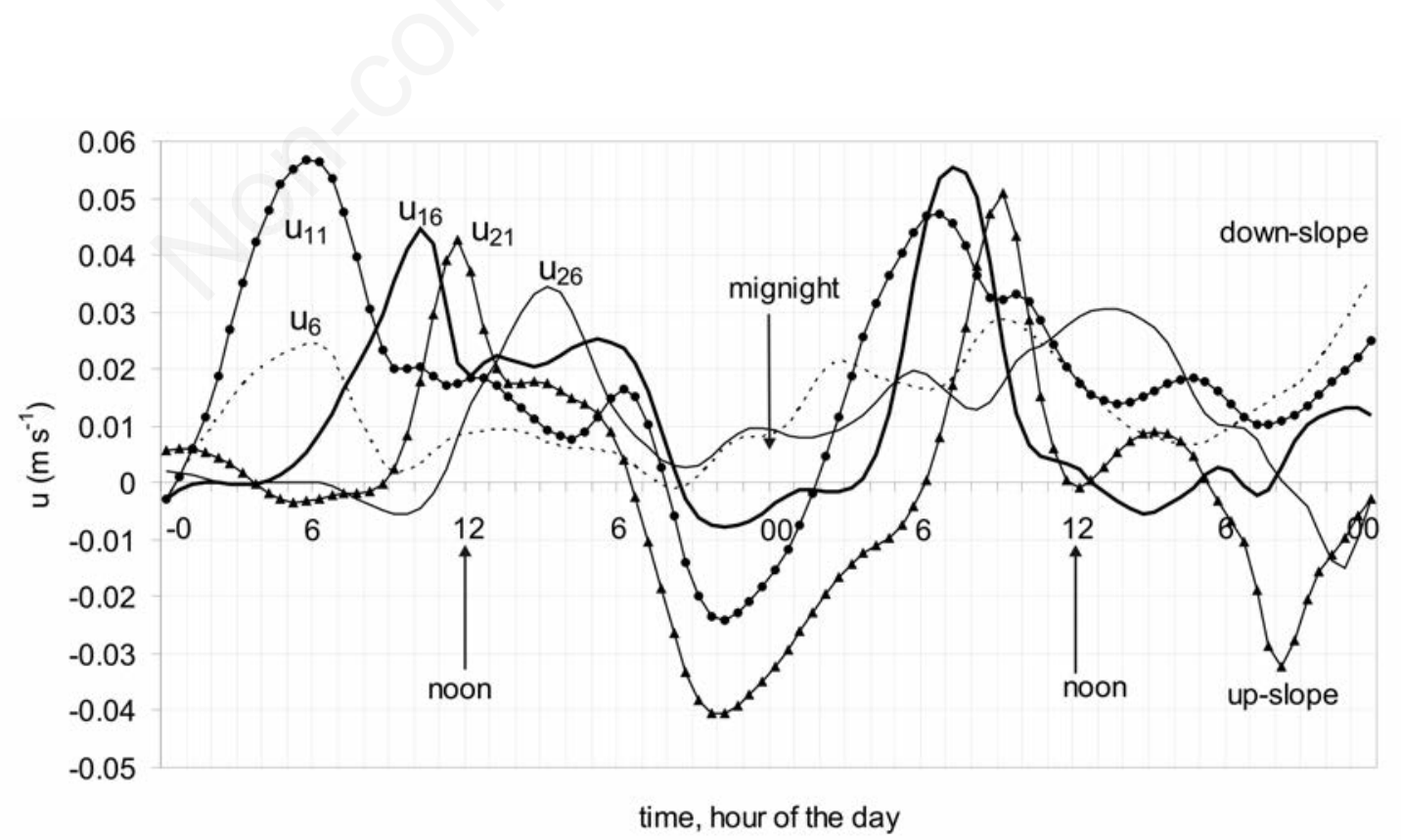

Fig. 5. Variations with time of horizontal cross-shore component of the flow velocity above (1.5 $\mathrm{m})$ the sloping bottom during 2 days (integrated values over every $30 \mathrm{~min}$ are shown). Positive values correspond to down-slope cascading, and negative values to up-slope motion. Indexes correspond to local depth in $\mathrm{m}$ (for locations, see Fig. 3). 
on the cooling intensity (i.e., values and time rate of change of the negative buoyancy flux through the surface). Mild and slow cooling causes moderate horizontal temperature gradients, and weaker (and vertically distributed) exchange flows, whilst intense and fast cooling produces larger horizontal gradients and faster flows (but with much narrower vertical distribution of the flow velocity), see e.g. laboratory experiments in Chubarenko and Demchenko (2008), Chubarenko (2010). In the first (mild-cooling) case, the dissipation rates of energy and momentum are very high, so that the Rossby radius (approx. $2 \mathrm{~km}$ here) as a limiting distance for current penetration into the lake body gives a significant overestimation. More realistic is to consider such a situation as a long-lasting process of volumetric cold-water generation and slow movement down the slope. In the second (intense-cooling) case, the denser waters are cooler (density excess is larger) and move faster; they penetrate and interleave deeper in stratified region, and can obviously propagate as isopycnal intrusions farther from the shore, to the distance defined by the energy balance: potential plus kinetic energy of the cold littoral water is to be dissipated through turbulent mixing and entrainment of surrounding stratified waters at the intrusion boundaries.

Obviously, instantaneous features of the considered convective flows, as well as particular pictures of formation and propagation of thermocline intrusions, are extremely variable, depending on many external conditions, and thus are difficult to quantify. For many applications, however, these details of the horizontal exchange are not as important as the general integrated picture: total volumetric water transport, its principal/smoothed temporal behaviour and spatial structure. We attempt to quantify them in the following section.

\section{Flow-rate of horizontal exchange}

Fig. 6 shows the development with time of the specific volumetric flow rate $\left(\mathrm{m}^{3} \mathrm{~s}^{-1} \mathrm{~km}^{-1}\right)$ through six vertical cross-sections of the basin (at local depths 6, 11, 16, 21, $26,31 \mathrm{~m})$. This means that, at every cross-section, the (off-shore) flow rate was first integrated over the basin width and local depth, and then divided by the basin width. This is done because the flow is not uniform over the basin width, but we are interested in averaged flowrate value.

The flow rate passes several phases in its development and manifests the day/night rhythm only in general. There are also irregular variations, secondary peaks, and time shifts of the main peaks, etc. (Fig. 6). Since the water was motionless at the beginning of the simulation, the numerical model required a certain heating-up period to develop first motions. This numerically conditioned period is about $8 \mathrm{~h}$ for the given basin/setup (Fig. 6). The first physical phase of exchange development is the appearance of the flow, then follows its adjustment to day/night buoyancy flux variations, and the last phase, the quasi-steady exchange, when variations of the flow rate in every next diurnal cycle look more or less like that of the previous day. For many applications, a very important parameter here is the duration of the development-and-adjustment

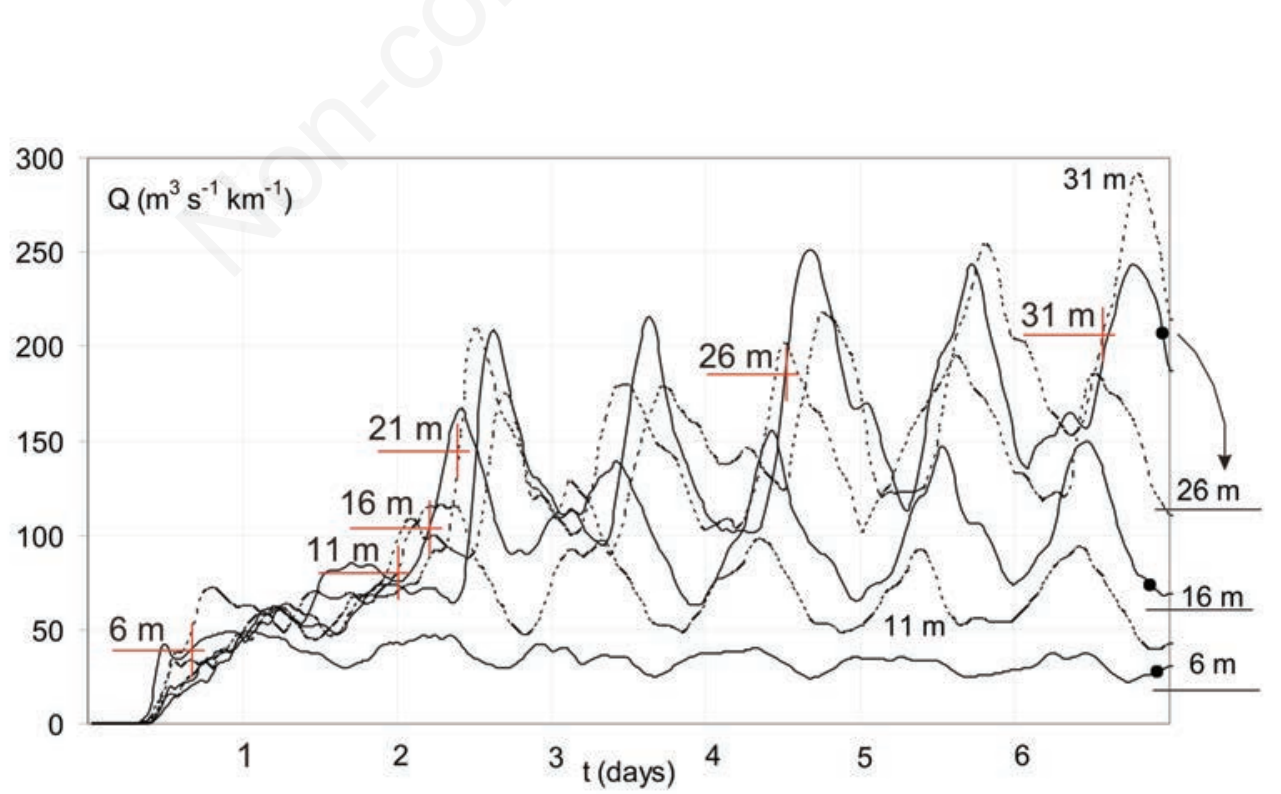

Fig. 6. Development with time of the flow rate $\mathrm{Q}\left[\mathrm{m}^{3} \mathrm{~s}^{-1} \mathrm{~km}^{-1}\right]$ of horizontal exchange through cross-sections in sloping area put at the depths $6,11,16,21,26$ and $31 \mathrm{~m}$. Horizontal bars on the right-hand side show the flow rate in quasi-steady state $\mathrm{Q}_{\mathrm{t}}$ under uniform cooling (without day/night oscillations), predicted by equation 2. Large crosses on the graphs indicate daily mean flow rate in quasisteady state with day/night oscillations $\mathrm{Q}_{\mathrm{qst}}$, and corresponding times when it is reached for the first time at the given cross-section. 
phase, which obviously depends on local depth (graphs on Fig. 6). In order to estimate it more accurately and for every local depth (cross-section), a 24-h running mean of flow rate during the quasi-steady state, $\mathrm{Q}_{\mathrm{qst}}$, was first calculated for every considered depth (cross-section). The time, when real curve $\mathrm{Q}(\mathrm{t})$ for the given cross-section intersects for the first time this quasi-steady-exchange level, was taken as the time of full development of the exchange at this local depth, $\tau$. The corresponding exchange $\mathrm{Q}_{\mathrm{qst}}$ and times $\tau$ for a number of local depths are shown in Fig. 6 (middle) and listed in Tab. 1 (first and second lines).

As seen in Tab. 1 (first row), the mean value of the flow-rate in the quasi-steady phase $\mathrm{Q}_{\mathrm{qst}}$ increases almost linearly with local depth. The level of this quasi-steady exchange is already crossed for the first time at depths of 6 and $11 \mathrm{~m}$ during the first day; at depths of 16-26 $\mathrm{m}$ this happens during the third day; and for depths more than $30 \mathrm{~m}$, almost 5 days are required (Tab. 1). What is important, after crossing of the quasi-steady level, the flow rate of the developing exchange flow rises further to maximum values, $\mathrm{Q}_{\text {peak }}$, which are even higher than the day maximum values in quasi-steady phase (Tab. 1). This peak exchange is about 1.5 times larger than the mean exchange in a quasi-steady regime, and about $10 \%$ larger than daily peak values in that time. It is observed in the shallowest part $(6 \mathrm{~m})$ during the first day, at intermediate depths (11-21 m) at the end of the second and during the third day, and at depths of 26-31 m after 4-6 days (Tab. 1). The quasi-steady exchange values $Q_{t}$, predicted by equation 2 (Tab. 1). are about twice as small as $\mathrm{Q}_{\mathrm{qs}}$, suggesting that the thermal siphon, energized by oscillating day/night buoyancy fluxes, works more efficiently than in the cases of (more or less) uniform external conditions in field observations and laboratory experiments, which lie behind the equation 2 (Chubarenko, 2010). Assuming the quasi-steady value of water exchange $\mathrm{Q}_{\mathrm{qs}}$, the times of full replacement of water in the coastal zone from the shore to the chosen cross-sections (or flushing times $\left.\tau_{\text {flush }}\right)$ can easily be calculated. They are shown in the last line of Tab. 1. Flushing time for the coastal triangle from the shoreline down to $6 \mathrm{~m}$ depth is about $12 \mathrm{~h}$ (first column, last line), which correlates very well with field observations of Monismith et al. (1990) in Wellington Reservoir: $14 \mathrm{~h}$ for the sidearm of 4-8 $\mathrm{m}$ depth.

\section{Phase diagrams for description of the day/night circulation}

Consideration of the day/night circulation as a convective process makes it logical to apply the so-called phase diagrams to its description. Such diagrams trace how two flow parameters vary with time (e.g., how velocity and temperature at certain points are related), and are very informative. Fig. 7 displays such a diagram relating the value of instantaneous off-shore flow rate (per $1 \mathrm{~m}$ of the shore length) through several cross-sections, $\mathrm{Q}$, and instant surface temperature difference $\Delta \mathrm{T}$ between cross-sections at 6 and $46 \mathrm{~m}, \Delta \mathrm{T}=\mathrm{T}_{46}-\mathrm{T}_{6}$. The process is traced during two full days (starting at noon, with $30 \mathrm{~min}$ time step) in the phase of fully developed exchange. Initial and final points of the curves in Fig. 7 are highlighted by larger markers, filled and empty, respectively. Overall, both long cooling and short heating periods of the day/night circle are present, with maximum shallow/deep temperature difference of about $0.65^{\circ} \mathrm{C}$ while cooling, and about $-0.05^{\circ} \mathrm{C}$ while heating. Surface temperature difference $\Delta \mathrm{T}$ appeared to be very close at initial and final time steps (coastal cooling, $\sim 0.17^{\circ} \mathrm{C}$ ), which is accidental. The time instants are separated by two days of oscillations, and at noon in between them, even coastal heating $(\sim$ $0.04^{\circ} \mathrm{C}$ ) took place. Maximum differential coastal cooling is observed at 0:30 (note: not after the cold night), with maximum heating at 15:30 (model noon is at 12:00). As it is seen, only at the 6-m-depth cross-section is the dependence between $\mathrm{Q}$ and $\Delta \mathrm{T}$ direct: a larger horizontal temperature gradient corresponds to a larger exchange rate. For deeper cross-sections, maximum $\mathrm{Q}$ never coincides, or is close in time with maximum of $\Delta \mathrm{T}$, and the lag between these maxima depends on the distance from the shore (in agreement with Farrow, 2004; Chubarenko,

Tab. 1. Characteristics of the exchange at six selected depths (cross-sections) above the slope: quasi-steady exchange levels $\mathrm{Q}_{\mathrm{qst}}$ (obtained by averaging over several day/night circles in quasi-steady phase); times $\tau$ of this quasi-steady exchange development; the peak values of flow rates $\mathrm{Q}_{\text {peak }}$ and the corresponding times $\tau_{\text {peak }}$; theoretical estimates of the quasi-steady exchange $\mathrm{Q}_{\mathrm{t}}($ equation 2 ); and the times $\tau_{\text {mix }}$, when vertical convection in the model reaches the bottom in the given cross-section (the equation 2 becomes applicable). Numerical heating-up period $(8 \mathrm{~h})$ is subtracted from all mentioned times.

\begin{tabular}{|c|c|c|c|c|c|c|}
\hline & $6 \mathrm{~m}$ & $11 \mathrm{~m}$ & $16 \mathrm{~m}$ & $21 \mathrm{~m}$ & $26 \mathrm{~m}$ & $31 \mathrm{~m}$ \\
\hline $\mathrm{Q}_{\mathrm{qst}}\left[\mathrm{m}^{3} \mathrm{~s}^{-1} \mathrm{~km}^{-1}\right]$ & 34 & 69 & 103 & 145 & 185 & 208 \\
\hline$\tau[\mathrm{h}]$ & 4 & 10 & 45 & 50 & 53 & 106 \\
\hline $\mathrm{Q}_{\text {peak }} / \mathrm{Q}_{\mathrm{qst}}$ & $48.5 / 34=1.43$ & $116 / 69=1.68$ & $167 / 103=1.62$ & $209 / 145=1.44$ & $251 / 185=1.36$ & $291 / 208=1.40$ \\
\hline$\tau_{\text {peak }}[\mathrm{h}]$ & 17 & 47 & 50 & 52 & 104 & 155 \\
\hline $\mathrm{Q}_{\mathrm{t}} / \mathrm{Q}_{\mathrm{qst}}$ & $15 / 34=0.44$ & $35 / 69=0.51$ & $58 / 103=0.56$ & $84 / 145=0.60$ & $113 / 185=0.61$ & $144 / 208=0.69$ \\
\hline$\tau_{\text {mix }}[\mathrm{h}]$ & 6 & 11 & 32 & 41 & 58 & 153 \\
\hline$\tau_{\text {flush }}[\mathrm{h}]$ & 12 & 22 & 32 & 40 & 49 & 62 \\
\hline
\end{tabular}


2010). This shows that the exchange currents are not in phase with the external forcing, and the whole picture is complex: diurnally oscillating (and even reversing) thermally induced pressure gradients interfere with dynamically built baroclinic pressure gradients, which results in highly nonlinear flow response. In Fig. 7, maximum flow rate through the 16-m-depth cross-section is reached at 12:30 (with time lag of $12 \mathrm{~h}$ after the maximum horizontal temperature difference), and through the 26-m-depth cross-section at 18:30 (time lag $18 \mathrm{~h}$ ). One may anticipate certain resonance effects when, in large lakes, vertical convection reaches depths of about 35-40 m, and the time lag of the development of horizontal exchange becomes close to the main day/night oscillation period.

Generally, for larger local depth above the sloping bottom, instant flow rates of horizontal exchange are also larger, in full agreement with theoretical predictions. On the right-hand side of Fig. 7, the quasi-steady exchange levels of horizontal flow rate according to equation 2 for every cross-section are shown, indicating that the formula gives values close to the minimum observed instant flow rates. As for dependency of $\mathrm{Q}$ on $\Delta \mathrm{T}$, the data in Fig. 7 displays a quite complicated relation. For the shallowmost cross-section at $6 \mathrm{~m}$ depth, the flow rate is minimal and almost constant when $\Delta \mathrm{T}$ (for both cooling and heating) is less than $0.1^{\circ} \mathrm{C}$. This minimum exchange is still twice as large as predicted by equation 2 . For larger $\Delta \mathrm{T}$, the flow-rate is related directly and linearly with $\Delta \mathrm{T}$, in the same manner in the phases of growing and falling $\Delta \mathrm{T}$. For deeper cross-sections, various day/night loops are obvious, and, generally, larger $\Delta \mathrm{T}$ correspond to smaller $\mathrm{Q}$, and maximum $\mathrm{Q}$ during a day is observed at small $\Delta \mathrm{T}$ (and often even in the heating phase). For the same $\Delta \mathrm{T}$, flow rates are different when $\mathrm{d}(\Delta \mathrm{T}) / \mathrm{dt}$ is positive and negative (i.e., in the phases of growing and falling $\Delta \mathrm{T}$ ), but in a different manner at $16 \mathrm{~m}$ and $26 \mathrm{~m}$ depth (Fig. 7, round arrows). In this way, for example, at the 26-mcross-section, the circle develops as follows: starting at noon (Fig. 7, large filled diamond, upper curve), the coastal-cooling $\Delta \mathrm{T}$ decreases and vanishes, while $\mathrm{Q}$ increases and reaches its daily maximum (at 6:30 p.m.). In the evening, the cooling- $\Delta \mathrm{T}$ gradually increases up to its maximum of $0.65^{\circ} \mathrm{C}$ (at about midnight), while $\mathrm{Q}$ decreases all this time, and 2-5 h more, and reaches the min-

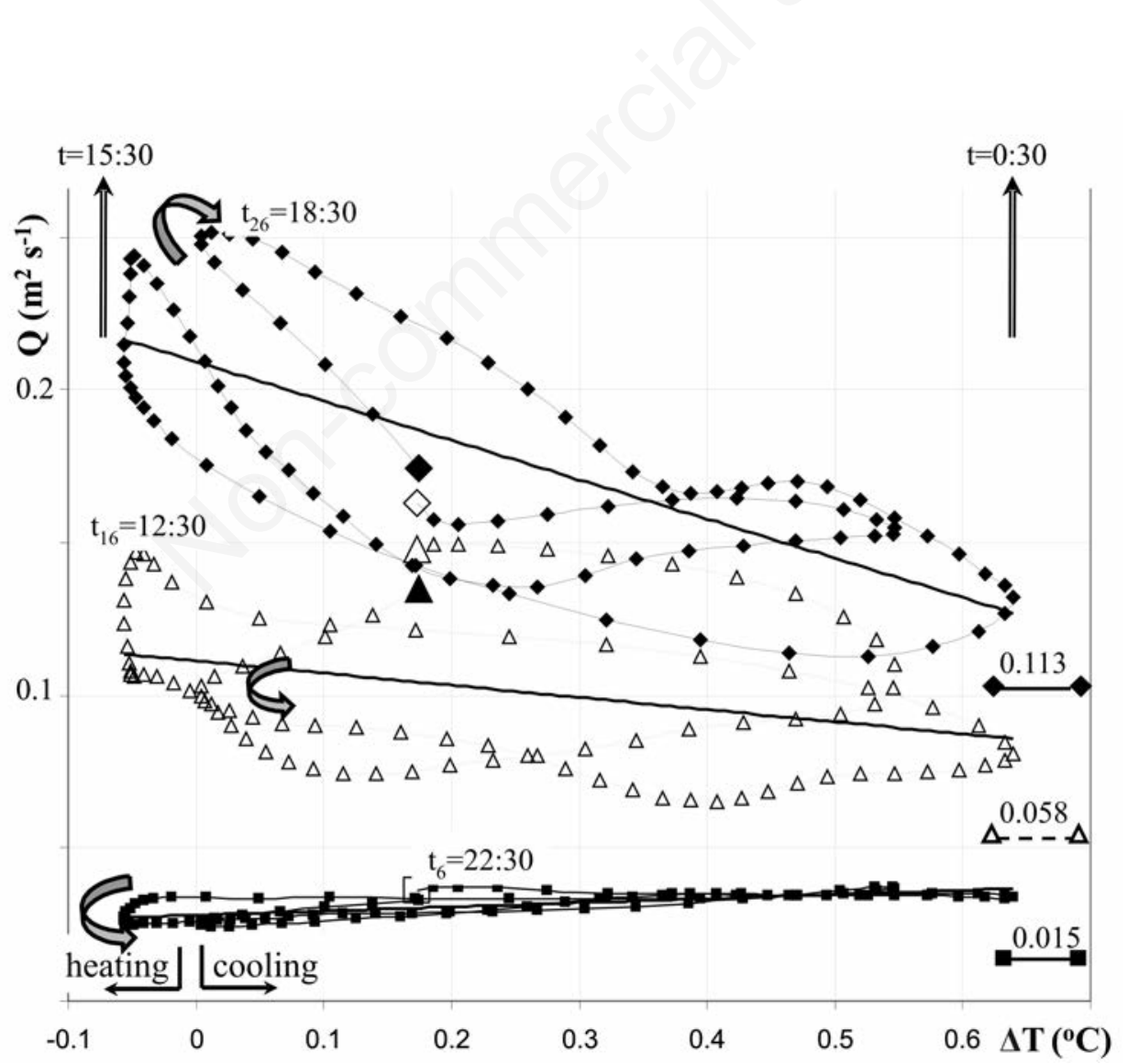

Fig. 7. Phase curve $\mathrm{Q}(\Delta \mathrm{T})$ for 2 days of the exchange process (points in $30 \mathrm{~min}$ ), plotted for the simulated data at 3 vertical crosssections, at depths of $6 \mathrm{~m}$ (filled squares), $16 \mathrm{~m}$ (open triangles) and $26 \mathrm{~m}$ (filled diamonds). Here, Q is instant off-shore flow rate (per $1 \mathrm{~m}$ of the shore length) through the given cross-section, and $\Delta \mathrm{T}$ is instant surface temperature difference between cross-sections at 6 and $46 \mathrm{~m}, \Delta \mathrm{T}=\mathrm{T}_{46}-\mathrm{T}_{6}$. Quasi-steady levels for every cross-section (according to equation 2) are shown on the right-hand side. 
imum (at 2:20-5:30 a.m.). Then in the morning (while $\Delta \mathrm{T}$ is decreasing), $\mathrm{Q}$ begins to grow, but the values are much smaller than those observed at the same $\Delta \mathrm{T}$ in the evening. Thus, the area of the loop reflects the lag of the exchange development.

The hysteresis of the curves in Fig. 7 characterizes not only the inertia of the process at different depths, but also the direction (clockwise or counterclockwise) in which it is passed, which provides certain insight in the physics of the process. Indeed, for $6 \mathrm{~m}$ and $16 \mathrm{~m}$ cross-sections, the circle is passed counter-clockwise: first $\Delta \mathrm{T}$ increases, then the down-slope flow develops and keeps large Q, maintained by (decreasing, but still supporting the flow) $\Delta T$ for longer times. In the case of the clockwise rotation (as it is for the $26 \mathrm{~m}$ cross-section), this logic does not work, and largest flows are observed after the period of decreasing and very small $\Delta \mathrm{T}$, which means that they are not directly driven by thermally induced pressure differences, but rather this water came along the slope from shallower areas. Thus, the presence of two dynamically different cells in such problems gets an additional explanation: in the shallower cell, the flow is driven mainly by external thermal/buoyancy forcing (with varying time lag, depending on local depth), whilst in the deeper cell, the flow is significantly contributed by down-slope currents from shallower regions, and mirrors the integrated result of larger-scale exchange. This larger-scale modulation makes instant flow features even more unpredictable. However, since the global shallow-deep exchange is proportional to the maximum depth above the slope, this deeper cell dynamics is of the main interest from the point of view of the shelf-sea (or littoral-pelagial) interaction. Hence, the general structural approach and estimative formulae, such as equation 2 , become of primary importance, as well as a careful comparison of such estimates with instant/peak/mean flow characteristics.

\section{CONCLUSIONS}

Sloping sides of natural basins favour the formation of horizontal temperature gradients (known as differential coastal heating or cooling), which cause significant littoral-pelagial water exchange, variable at day/night, synoptic and seasonal time scales. Autumnal denser water cascading along the sloping lake boundary, modulated by day/night variations of solar heating, was simulated in order to reveal the development of the cascading process in time, spatial structure of the exchange flows, and diurnal variations of volumetric flow rate of the littoral-pelagial exchange flows, as well as to compare its daily maxima at different depths with known quasi-steady state estimates.

The development of the exchange flow under day/night variations of the surface buoyancy flux passes two phases: i) appearance of structured exchange and its adjustment to day/night buoyancy flux variations; and ii) the quasi-steady exchange, when variations of the flow rate in every next diurnal cycle are more or less the same as on the previous day. Duration of the appearance-andadjustment phase depends on local depth: down to depths of about $10 \mathrm{~m}$ the convective exchange is already fully developed after one day of day/night oscillations, down to $15-25 \mathrm{~m}$ after 3 days, and down to $30 \mathrm{~m}$ after 5 days (for the considered linear initial vertical temperature stratification).

Maximum horizontal exchange takes place in the region above the point where the thermocline meets the slope, and cold down-slope currents detach from the bottom. Its location advances off-shore with time, in accordance with deepening of the upper mixed layer. A characteristic feature of horizontal convective exchange is the existence of a specific coastal circulation cell with water dynamics different from that above the main part of the slope. However, it is unimportant for general littoral-pelagial (or shelf/sea) water exchange, since the latter is driven by processes above the main part of the slope rather than in this most shallow coastal cell.

The mean value of the flow rate of the convective exchange, driven by day/night oscillations, in its quasisteady phase, increases with local depth almost linearly, being about twice as large as the quasi-steady exchange values, predicted by equation 2 , suggesting that the thermal siphon, energized by oscillating day/night buoyancy fluxes, flushes coastal regions more efficiently than just the cascading driven by (more or less) uniform external conditions in field observations and laboratory experiments, which lie behind the equation 2 (Chubarenko, 2010). Flushing time in the considered case has an order of 10-60 hours for the littoral zone of 6-30 m depth.

Application of phase diagrams for the description of the day/night convective exchange flows, at different depths above sloping bottom, is very informative, allowing for visualization of the flow development process, its coherency in different cross-sections, time lag of the development, and other general features.

\section{ACKNOWLEDGMENTS}

The authors kindly acknowledge the financial support of AAA of Rostock University, which has allowed a research visit of I. Chubarenko to the Zingst Biological Station. The work is supported by RFBR, grants N. 13-05 01041a and 12-05-90820-mol_rf_nr.

\section{REFERENCES}

Baines PG, 2001. Mixing in flows down gentle slopes into stratified environments. J. Fluid Mech. 443:237-270.

Baines PG, 2005. Mixing regimes for the flow of dense fluid down slopes into stratified environments. J. Fluid Mech. 538:245-267. 
Carmack EC, Farmer DM, 1982. Cooling process in deep, temperate lakes: A review with examples from two lakes in British Columbia. J. Marine Res. 40:85-111.

Chorin AJ, 1967. A numerical method for solving incompressible viscous flow problems. J. Comp. Physics 2:12-26.

Chubarenko I, 2010. Horizontal convective water exchange above sloping bottom: the mechanism of its formation and an analysis of its development. Oceanology 50:166-174.

Chubarenko I, Chubarenko B, Bäuerle E, Wang Y, Hutter K, 2003. Autumn physical limnological experimental campaign in the Island Mainau littoral zone of Lake Constance. J. Limnol. 62:115-119.

Chubarenko I, Demchenko N, 2008. Laboratory modelling of the structure of a thermal bar and related circulation in a basin with a sloping bottom. Oceanology 48:349-361.

Chubarenko IP, Demchenko NY, 2010. On contribution of horizontal and intra-layer convection to the formation of the Baltic Sea cold intermediate layer. Ocean Sci. 6:285-299.

Chubarenko I, Hutter K, 2005. Thermally driven interaction of the littoral and limnetic zones by autumnal cooling process. J. Limnol. 64:31-42.

Farrow DE, 2004. Periodically forced natural convection over slowly varying topography. J. Fluid Mech. 508: 1-21.

Farrow DE, Patterson JC, 1993. On the response of a reservoir sidearm to diurnal heating and cooling. J. Fluid Mech. 246:143-161.

Fer I, Lemmin U, Thorpe SA, 2002. Winter cascading of cold water in Lake Geneva. J. Geophys. Res. 107:2236-2569.
Horsch GM, Stefan HG, 1988. Convective circulation in littoral water due to surface cooling. Limnol. Oceanogr. 33:10681083.

Horsch GM, Stefan HG, Gavali S, 1994. Numerical simulation of cooling-induced convective currents on a littoral slope. Int. J. Num. Meth. Fl. 19:105-134.

Hughes GO, Griffiths RW, 2008. Horizontal convection. Annu. Rev. Fluid Mech. 40:185-208.

Imberger J, Hamblin P, 1982. Dynamics of lakes, reservoirs and cooling ponds. Ann. Rev. Fluid Mech. 14:153-187.

Lei C, Patterson JC, 2006. Natural convection induced by diurnal heating and cooling in a reservoir with slowly varying topography. JSME Int. J. B-Fluid T. 49:605-615.

Monismith S, Imberger J, Morison M, 1990. Convective motions in the sidearm of a small reservoir. Limnol. Oceanogr. 35:1676-1702.

Mullarney JC, Griffiths RW, Hughes GO, 2004. Convection driven by differential heating at a horizontal boundary. J. Fluid Mech. 516:181-209.

Rossby HT, 1965. On thermal convection driven by non-uniform heating from below: an experimental study. Deep-Sea Res. 12:9-16.

Sturman JJ, Oldham CE, Ivey GN, 1999. Steady convective exchange flows down slopes. Aquat. Sci. 61:260-278.

Thorpe SA, 1998. Some dynamical effects of internal waves and the sloping sides of lakes. p. 441-460. In: J.Imberger (ed.), Physical processes in lakes and oceans. American Geophysical Union. 